\title{
Inovulação de embriões bovinos recém-colhidos em receptoras tratadas com rbST no dia do estro ${ }^{1}$
}

\author{
Paulo Alexandre Fernandes Marques ${ }^{2}$, Eduardo Paulino da Costa ${ }^{3}$, Carlos Antônio de \\ Carvalho Fernandes ${ }^{4}$, Tarcízio Antônio Rêgo de Paula ${ }^{3}$, José Rogério Moura de Almeida \\ Neto $^{2}$, Giancarlo Magalhães dos Santos ${ }^{2}$
}

\footnotetext{
1 Fonte de financiamento: FAPEMIG - Fundação de Amparo à Pesquisa do Estado de Minas Gerais.

2 Programa de Pós-Graduação em Veterinária, DVT/UFV - Viçosa - MG.

${ }^{3}$ Departamento de Veterinária/UFV - Viçosa - MG.

${ }^{4}$ Biotran - Biotecnologia e Treinamento em Reprodução Animal - Alfenas - MG.
}

RESUMO - Estudou-se o efeito da administração de rbST no dia do estro, na taxa de gestação e concentração sérica de progesterona em fêmeas bovinas receptoras de embrião. A administração subcutânea de rbST (500 mg) foi realizada em 67 receptoras, mantendo-se 77 sem administração de rbST (144 receptoras no total). Os diagnósticos de gestação foram realizados aos 30 dias após o estro e as taxas de gestação diferiram entre as receptoras: 32,5\% (25 das 77 sem administração de rbST) e 65,7\% (44 das 67 receptoras tratadas com rbST). As concentrações séricas de progesterona obtidas nas amostras de sangue coletadas no dia da inovulação não diferiram com a administração de rbST: 2,54 \pm 0,19 ng/mL (sem rbST) e 2,27 $\pm 0,20 \mathrm{ng} / \mathrm{mL}$ (com rbST). Esses resultados indicam que a administração de $500 \mathrm{mg}$ de rbST no dia do estro aumenta a taxa de gestação, mas não influencia a concentração sérica de progesterona de receptoras de embriões recém-colhidos.

Palavras-chave: progesterona, taxa de gestação

\section{Inovulation of bovine embryos recently collected in receiving treated with rbST in the estrus day}

\begin{abstract}
This study aimed to analyze the effects of rbST administration in the estrous day, on pregnancy rate and progesterone concentration in cows embryo receivers. The subcutaneously administration of rbST (500 mg) was done in 67 receivers, and 77 without the rbST administration (144 receivers totally). The pregnancy determination was done 30 days after the estrous day and the pregnancy rate was different between the treatments where: $32.5 \%$ (25 from 77 without rbST administration) and 65.7\% (44 from 67 receivers treated with rbST). The serum progesterone concentration from the blood samples collected on the embryo transfer day were not different in presence of rbST treatment: $2.54 \pm 0.19 \mathrm{ng} / \mathrm{mL}$ (without $\mathrm{rbST}$ ) and $2.27 \pm 0.20 \mathrm{ng} / \mathrm{mL}$ (rbST). In brief, these results suggests that $500 \mathrm{mg}$ of rbST administration on the estrous day increase the pregnancy rate, however it does not have influence on serum progesterone concentration in cows receiver of fresh embryos.
\end{abstract}

Key Words: pregnancy rate, progesterone

\section{Introdução}

No intuito de elevar a eficiência econômica da pecuária nacional, tem-se procurado utilizar novas tecnologias para aumentar os ganhos genéticos do rebanho. Neste contexto, biotecnologias reprodutivas como a transferência de embriões destacam-se pela diminuição do intervalo de gerações e pelo rápido progresso genético. Entretanto, em programas de transferência de embriões, é dada atenção especial às doadoras, ao contrário das receptoras, que são relegadas ao segundo plano (Fernandes, 1999), prática que tem refletido sobre os baixos índices de gestação alcançados com esta tecnologia, principalmente pela elevada incidência de morte embrionária, nas três primeiras semanas de gestação (Sreenan \& Diskin, 1987).

Desse modo, as taxas de gestação com o uso de embriões oriundos de procedimentos de transferência de embriões são menores que as obtidas por inseminação artificial ou monta natural (Peterson \& Lee, 2003). Considerando que o estabelecimento e a manutenção da gestação envolvem complexa interação entre o embrião, o ambiente uterino e o corpo lúteo (Mann et al., 1995), a menor taxa de 
gestação utilizando-se a transferência de embriões pode estar associada ao subdesenvolvimento dos embriões, à assincronia útero-embrião e à má qualidade do corpo lúteo (CL) das receptoras (Sreenan \& Diskin, 1987), resultando em falhas no mecanismo de reconhecimento materno da gestação (Thatcher et al., 1995). Para o estabelecimento da gestação, é necessária a produção de fatores de reconhecimento materno da gestação (Mann et al., 1995). Entre eles, destaca-se o interferon-tau (IFN- $\tau$ ), que age na manutenção da gestação (Thatcher et al., 2001). Assim, o atraso ou a insuficiência de sua secreção podem ser responsáveis por morte embrionária prematura (Arnold et al., 2000).

No intuito de prevenir maiores perdas embrionárias, vários autores têm sugerido a utilização da somatotropina bovina recombinante (rbST), que participa dos processos fisiológicos e metabólicos (Davis, 1998), aumentando as concentrações de somatotropina (bST), do fator de crescimento semelhante à insulina (IGF-I) e a freqüência de pulsos do hormônio luteinizante (LH) (Moreira et al., 2002).

Esta substância, aplicada no período pós-inseminação, aumenta direta ou indiretamente a concentração de IFN- $\tau$ no lúmen uterino, as taxas de prenhez e o tamanho do concepto e aceleram o desenvolvimento do embrião (Bilby et al., 2004a,b). Neste trabalho, objetivou-se avaliar o efeito da administração de $500 \mathrm{mg}$ de rbST no dia do estro em receptoras de embrião bovino recém-colhido na concentração sérica de progesterona $\left(\mathrm{P}_{4}\right)$ e na taxa de gestação.

\section{Material e Métodos}

Foram utilizadas 16 doadoras para a transferência de embriões (12 da raça Guzerá, 3 Red Angus e 1 Simental Sulafricano), todas com peso corporal acima de $500 \mathrm{~kg}$. O tratamento hormonal teve início com a aplicação de dispositivo intra-vaginal de progesterona. No dia seguinte, foram administrados $3 \mathrm{mg}$ de benzoato de estradiol via intramuscular. No quinto dia da aplicação do dispositivo $\mathrm{P}_{4}$, deu-se início ao protocolo de superovulação, com a administração de doses decrescentes de FSH, em intervalos de 12 horas, perfazendo um total de oito aplicações. Juntamente com a sétima e oitava aplicações de FSH, foi injetado 0,530 mg de cloprostenol sódico para a indução da luteólise. Concomitante à oitava aplicação, foi removido o implante de progesterona. Após o início do estro, foi administrado $0,0084 \mathrm{mg}$ de acetato de buserelina e realizadas duas inseminações: a primeira 10 a 12 horas e a segunda 20 a 24 horas após o início do estro.

Os embriões foram inovulados em 144 receptoras mestiças (vacas e novilhas), com bom escore corporal (escala de 1 a 5) (Ferreira, 1990) e peso corporal acima de $350 \mathrm{~kg}$, previamente selecionadas por exame ginecológico e observadas por dois ciclos estrais completos. As receptoras foram alojadas em piquetes em regime de pastejo, predominantemente de capim-braquiária (Brachiaria brizanta), com fornecimento de sal mineral e água à vontade. As fêmeas se encontravam entre o $7 \underline{0}$ e $17 \underline{0}$ dia do ciclo estral e receberam a aplicação de 0,530 mg de cloprostenol sódico, via intra-muscular, 24 horas antes da aplicação da mesma droga nas doadoras. A detecção do estro dos animais foi realizada visualmente, com o auxílio de rufiões, duas vezes ao dia (início da manhã e final da tarde), por um período mínimo de 30 minutos.

Dos animais que apresentaram comportamento de estro, 77 foram mantidos como animais controle e 67 como receptoras de embrião, com aplicação de 500 mg de rbST no dia do estro. No $7 \underline{0}$ dia, as receptoras foram inovuladas com embriões de qualidade 1, 2 ou 3 (excelente, bom ou regular) pelo método transcervical (ou não cirúrgico).

As coletas de sangue para dosagem de $\mathrm{P}_{4}$ foram realizadas no momento das inovulações dos embriões, em tubos vacuolizados de $10 \mathrm{~mL}$, sem anticoagulante, via punção da artéria ou veia coccígea e estocados em isopor em temperatura de 5 a $8^{\circ} \mathrm{C}$. Após a centrifugação a $1.700 \mathrm{G}$ por 10 minutos, os soros foram acondicionados em microtubos identificados e estocados a temperatura de $-20^{\circ} \mathrm{C}$. As amostras de soro sangüíneo foram submetidas à análise de $\mathrm{P}_{4}$ utilizando-se o kit comercial de radioimunoensaio (RIA) em fase sólida no Laboratório de Preparo de Amostras e Radioimunoensaio da Empresa Brasileira de Pesquisa Agropecuária (EMBRAPA) - Gado de Leite (Centro Nacional de Pesquisa de Gado de Leite - CNPGL). Os diagnósticos de gestação foram realizados 30 dias após o estro das receptoras, por meio de exames ultra-sonográficos.

As taxas de gestação foram arranjadas em tabelas de contingência e, posteriormente, submetidas à análise pelo teste de Qui-quadrado a 5\% de probabilidade de erro. Para análise das concentrações séricas de $\mathrm{P}_{4}$, utilizou-se o programa SAEG 8.0 (2000). Os dados foram submetidos aos testes de Normalidade (Lillefors) e Homocedasticidade (Cochram e Bartlet) e posteriormente analisados pelo teste $\mathrm{F}$, adotando-se $5 \%$ de probabilidade.

\section{Resultados e Discussão}

As taxas de gestação das receptoras de embrião, detectadas aos 30 dias após o estro por meio de ultra-sonografia, foram de 32,5\% (25/77) nos animais controle e 65,7\% (44/67) nas receptoras tratadas com rbST. Os valores observados apresentaram diferença $(\mathrm{P}<0,01)$ pelo teste de qui-quadrado (Tabela 1). 
Tabela 1 - Número de animais e taxas de gestação em receptoras de embrião recém-colhido tratadas ou não tratadas com rbST (500 mg) no dia do estro

\begin{tabular}{lcc}
\hline Tratamento & Número de animais & Gestantes (\%) \\
\hline Controle & 77 & 32,5 \\
rbST & 67 & 65,7 \\
\hline
\end{tabular}

Diferenças observadas entre os grupos $(\mathrm{P}<0,01)$ pelo teste de qui-quadrado.

A taxa de gestação obtida com o uso da rbST (65,7\%) foi similar à observada por Fonseca et al. (2001a). Esses autores administraram $500 \mathrm{mg}$ de rbST no quinto dia do ciclo em novilhas receptoras e obtiveram taxas de gestação de 60,0 e $62,5 \%$ nos grupos tratados e controle, respectivamente, porém sem diferença. Hasler et al. (2003) também utilizaram a mesma dose em novilhas no momento da inovulação e também não observaram aumento na taxa de gestação.

Entretanto, Moreira et al. (1997, 2002) observaram que a aplicação de rbST nas receptoras de embriões aumenta as concentrações de IGF-1 e bST e as taxas de fertilização, acelerando o desenvolvimento embrionário e melhorando a qualidade do embrião. Neste contexto, maior desenvolvimento embrionário inicial é importante para melhor sinalização do embrião no útero materno e contribui para o reconhecimento materno da gestação (Roberts et al., 1992). Esta condição foi verificada por Thatcher et al. (2006), que observaram aumento na concentração de INF- $\tau$ no fluido uterino após a administração de 500 mg de rbST. Adicionalmente, estes mesmos autores encontraram maior concentração plasmática de IGF-1 em vacas gestantes ( $261 \pm 18 \mathrm{ng} / \mathrm{mL})$ em comparação a vacas não-gestantes $(211 \pm 17 \mathrm{ng} / \mathrm{mL})$ e esta diferença pode ter contribuído para o estabelecimento da gestação, em razão do aumento no desenvolvimento embrionário (Moreira et al., 1997, 2002).

Segundo Moreira et al. (2000), a ação da rbST, IGF-1 ou de ambas promove aceleração no crescimento embrionário e aumento no número de células trofoblásticas, elevando a secreção de INF- $\tau$ pelo embrião, aumentando a inibição no processo de luteólise (Mann \& Lamming, 2001) e contribuindo para melhores índices reprodutivos.

Os receptores para bST e IGF-1 estão presentes no endométrio de vacas (Wathes et al., 1998) e, em alta concentração, nas glândulas epiteliais uterinas, o que sugere uma função para o IGF-1 na regulação da atividade secretória das glândulas endometriais, auxiliando na manutenção da gestação, em virtude da melhoria no ambiente uterino (Moreira et al., 2002). Além disso, o INF- $\tau$ é responsável pela atenuação na secreção de prostaglandina F2 $\alpha$ (PGF2 $\alpha$ ) oriunda do tecido endometrial (Thatcher et al., 1997), impedindo o processo de luteólise no momento do reconhecimento materno da gestação, pela manutenção das concentrações elevadas de $\mathrm{P}_{4}$, o que favorece a implantação do concepto e a manutenção da gestação (Moreira et al., 2002).

A concentração média de $\mathrm{P}_{4}$ entre os grupos controle (T1) e tratado (T2) não foi diferente $(\mathrm{P}>0,05)$ (Tabela 2).

A concentração média de progesterona nas receptoras de embrião dos grupos controle e tratadas com $500 \mathrm{mg}$ de rbST foi similar $(\mathrm{P}>0,05)$ tanto para as receptoras gestantes quanto para não-gestantes (Tabela 3 ).

Resultados similares para a concentração média de $\mathrm{P}_{4}$ foram observados por Morales-Roura et al. (2001) com administração de rbST no dia do estro em vacas receptoras de embrião em lactação e por Starbuck et al. (2006) com aplicação no momento da inseminação, no entanto, não foram observados aumentos na concentração sérica de $\mathrm{P}_{4}$.

Fonseca et al. (2001b) administraram $500 \mathrm{mg}$ de rbST no quinto dia do ciclo estral em novilhas receptoras e não obtiveram diferenças entre grupos tratados e controle. Entretanto, esses autores utilizaram somente novilhas, em vez de diferentes categorias como neste estudo, o que, de acordo com Lucy et al. (1994), pode interferir na concentração de $\mathrm{P}_{4}$, uma vez que novilhas apresentam concentrações endógenas de IGF-I superiores às de vacas em lactação (Gallo \& Block, 1991), pois a capacidade esteroidogênica de seus ovários é comprometida pela lactação (Lucy et al., 1995).

Entretanto, vacas lactantes tratadas com $500 \mathrm{mg}$ de rbST no momento da inseminação e 11 dias após, apresentaram decréscimo na concentração sérica de $\mathrm{P}_{4}$, o que pode

Tabela 2 - Concentração média de progesterona sérica (ng/mL) no dia da inovulação nas receptoras

\begin{tabular}{lc}
\hline Tratamento & Progesterona $\left(\mathrm{P}_{4}\right)(\mathrm{ng} / \mathrm{mL})$ \\
\hline Controle & $2,54 \pm 0,19$ \\
rbST & $2,27 \pm 0,20$ \\
\hline
\end{tabular}

Não houve diferença entre grupos $(\mathrm{P}>0,05)$ pelo teste $\mathrm{F}$.

Tabela 3 - Concentração média de progesterona sérica no dia da inovulação (sétimo dia após o estro) em receptoras gestantes e não gestantes

\begin{tabular}{lcc}
\hline Tratamento & \multicolumn{2}{c}{ Progesterona $\left(\mathrm{P}_{4}\right)(\mathrm{ng} / \mathrm{mL})$} \\
\cline { 2 - 3 } & Gestante* & Não-gestante* \\
\hline Controle & $2,91 \pm 0,30$ & $2,24 \pm 0,27$ \\
rbST & $2,12 \pm 0,21$ & $2,60 \pm 0,31$ \\
\hline * A distribuição dos animais em gestantes e não-gestantes, em cada grupo, foi \\
definida após o diagnóstico de gestação realizado no 30ㅇ dia após o estro, por \\
meio de exames ultra-sonográficos. \\
Não houve diferença entre receptoras gestantes e não-gestantes do mesmo grupo \\
(P>0,05) pelo teste F.
\end{tabular}


estar associado a aumento na taxa de metabolismo geral do animal, induzido pelo rbST (Thatcher et al., 2006). Veldhuis et al. (1986), no entanto, afirmaram que o tratamento com rbST estimula a síntese de $\mathrm{P}_{4}$, em virtude do aumento na concentração de IGF-I, a qual geralmente se encontra em baixa concentração em vacas em lactação (Gallo \& Block, 1991). Sabe-se que a IGF-I é fundamental no aumento da captação e absorção de lipoproteínas e na esteriodogênese da célula da granulosa e luteal, o que aumenta a síntese de $\mathrm{P}_{4}$ (Veldhuis et al., 1986).

Por isso, é possível que o dia do ciclo estral em que a rbST foi aplicada também seja um fator responsável pelo não aumento da concentração sérica de progesterona. Neste experimento, a administração da rbST realizada no dia do estro não aumentou a concentração sérica desse esteróide. Corroborando, estudos têm comprovado ausência de elevação na concentração de $\mathrm{P}_{4}$ ao ser administrada somatotropina no momento do estro (Starbuck et al., 2006; Haas, 2004; Morales-Roura et al., 2001) ou no quinto dia do ciclo estral (Fonseca et al., 2001b).

Ainda que não tenha promovido aumento na concentração de $\mathrm{P}_{4}$, a administração de 500 mg de rbST no momento do estro aumentou a taxa de gestação dos animais tratados. De acordo com Staples \& Hansel (1961), a concentração de $\mathrm{P}_{4}$ deve estar em patamares limiares ou adequados para que haja desenvolvimento embrionário normal, desse modo, em concentrações abaixo desse limiar, a gestação não se estabelece. No entanto, alcançando uma concentração adequada, novos incrementos na concentração podem não promover efeito aditivo na taxa de gestação.

\section{Conclusões}

A administração de $500 \mathrm{mg}$ de rbST no dia do estro em receptoras inovuladas com embrião recém-colhido melhora a taxa de gestação, apesar de não aumentar a concentração sérica de progesterona.

\section{Agradecimentos}

À FAPEMIG, pelo suporte financeiro.

\section{Literatura Citada}

ARNOLD, D.R.; BINELLI, M.; VONK, J. et al. Intracellular regulation of endometrial PGF $2 \alpha$ production in dairy cows during early pregnancy and following treatment with recombinant interferon- $\tau$. Domestic Animal Endocrinology, v.18, p.199-216, 2000.

BILBY, T.R.; GUZELOGLU, A.; MICHEL, F. et al. Effects of bovine somatotropin (bST), pregnancy and a diet enriched in omega-3 fatty acids on endometrial gene expression at day 17 after ovulation in lactating dairy cows. Biology of Reproduction (special issue),v. 278, (abstract), 2004a.

BILBY, T.R.; MICHEL, F.; JENKINS, T. et al. Effects of bovine somatotropin (bST), pregnancy and a diet enriched in omega-3 fatty acids on the uterine GH system in lactating dairy cows. Journal of Dairy Science, v.87 (suppl), n.197 (abstract), 2004b.

DAVIS, S.L. Recent concepts in regulation of growth by GH and IGF. Journal of Animal Science, v.66, p.84-97, 1998 (suppl. 3).

FERNANDES, C.A.C. Inovulações não cirúrgicas e taxa de gestação de receptoras de embrião. Arquivo Brasileiro de Medicina Veterinária e Zootecnia, v.51, n.3, p.263-266, 1999.

FERREIRA, A.M. Efeito da amamentação e do nível nutricional na atividade ovariana de vacas mestiças leiteiras. 1990. 134f. Tese (Doutorado em Zootecnia) - Universidade Federal de Viçosa, Viçosa, MG, 1990.

FONSECA, J.F.; SILVA FILHO, J.M.; PINTO NETO, A. et al. Taxas de gestação de novilhas receptoras submetidas à administração de rbST, GnRH ou hCG no quinto dia do ciclo estral. Arquivo Brasileiro de Medicina Veterinária e Zootecnia, v.53, n.4, p.459-464, 200la.

FONSECA, J.F.; SILVA FILHO, J.M.; PALHARES, M.S. et al. Concentração plasmática de progesterona em novilhas receptoras submetidas à administração de rbST, GnRH ou hCG no quinto dia do ciclo estral. Arquivo Brasileiro de Medicina Veterinária e Zootecnia, v.53, n.4, p.451-458, 2001b.

GALLO, G.F.; BLOCK, E. Effects of recombinant bovine on hypophyseal and ovarian functions of lactating dairy cows. Canadian Journal of Animal Science, v.71, p.343-353, 1991.

HAAS, G.T.S. Taxa de gestação e concentração sérica de progesterona em receptoras de embrião bovino tratadas com somatotropina recombinante bovina (rbST). 2004. 38f. Dissertação (Mestrado em Medicina Veterinária) Universidade Federal de Viçosa, Viçosa, MG, 2004.

HASLER, J.F.; BILBY, C.R.; COLLIER, R.J. et al. Effect of recombinant bovine somatotropin on superovulatory response and recipient pregnancy rates in a commercial embryo transfer program. Theriogenology, v.59, p.1919-1928, 2003.

LUCY, M.C.; CURRAN, I.T.; COLLIER, R.J. et al. Extended function of the corpus luteum and advanced follicular development in heifers treated with bovine somatotropin. Theriogenology, v.41, p.561-572, 1994.

LUCY, M.C.; THATCHER, W.W.; COLLIER, R.J. et al. Effects of somatotropin on the conceptus, uterus, and ovary during maternal recognition of pregnancy in cattle. Domestic Animal Endocrinology, v.12, p.73-82, 1995.

MANN, G.E.; LAMMING, G.E. Relationship between maternal endocrine environment, early embryo development and inhibition of luteolytic mechanism in cows. Reproduction, v.121, p.175-180, 2001.

MANN, G.E.; LAMMING, G.E.; FRAY, M.D. Plasma oestradiol and progesterone during early pregnancy in the cow and the effects of treatment with buserelin. Animal Reproduction Science, v.37, p.121-131, 1995.

MORALES-ROURA, J.S.; ZARCO, L.; HERNÁNDEZ-CERÓN, J. et al. Effect of hort-term treatment with bovine somatotropin at estrus on conception rate and luteal function of repeat-breeding dairy cows. Theriogenology, v.55, p.1831-1841, 2001.

MOREIRA, F.; BADINGA, L.; BURNLEY, C. et al. Bovine somatotropin increases embryonic development in superovulated cows and improves post-transfer pregnancy rates when given to lactating recipient cows. Theriogenology, v.57, p.1371-1387, 2002.

MOREIRA, F.; RISCO, C.A.; PIRES, M.F.A. et al. Use of bovine somatotropin in lactating dairy cows receiving timed artificial insemination. Journal of Dairy Science, v.83, p.1234-1247, 2000.

MOREIRA, F.; RISCO, C.A.; PIRES, M.F.A. et al. Use of timed insemination in lactating dairy cows receiving bovine somatotropin. Journal of Dairy Science, v.80, p.239 abstr, 1997 (suppl. 1). 
PETERSON, A.J.; LEE, R.S-F. Improving successful pregnancies after embryo transfer. Theriogenology, v.59, p.687-697, 2003.

ROBERTS, R.M.; CROSS, J.C.; LEAMAN, D.W. Interferons as hormones of pregnancy. Endocrine Reviews, v.13, p.432-452, 1992.

SREENAN, J.M.; DISKIN, M.G. Factors affecting pregnancy rate following embryo transfer in the cow. Theriogenology, v.27, p.99-113, 1987.

STAPLES, R.E.; HANSEL, W.W. Luteal function and embryo survival in the bovine. Journal of Dairy Science, v.44, p.2040, 1961.

STARBUCK, M.J.; KEITH INSKEEP, E.; DAILEY, R.A. Effect of a single growth hormone (rbST) treatment at breeding on conception rates and pregnancy retention in dairy and beef cattle. Animal Reproduction Science, v.93, p.349-359, 2006.

THATCHER, W.W.; BILBY, T.R.; BARTOLOME, J.A. Strategies for improving fertility in the modern dairy cow. Theriogenology, v.65, p.30-44, 2006.
THATCHER, W.W.; BINELLI, M.; BURKE, J. et al. Antiluteolytic signals between the conceptus and endometrium. Theriogenology, v.47, p.131-140, 1997.

THATCHER, W.W.; GUZELOGLU, A.; MATTOS, R. et al. Uterineconceptus interactions and reproductive failure in cattle. Theriogenology, v.56, p.1435-1450, 2001.

THATCHER, W.W.; MEYER, M.D.; DANET-DESNOYERS, G. Maternal recognition of pregnancy. Journal of Reproduction and Fertility, v.49, p.15-28, 1995.

UNIVERSIDADE FEDERAL DE VIÇOSA - UFV. Sistema de análise estatística e genética - SAEG. Versão 8.0. Viçosa, MG: 2000. 142p.

VELDHUIS, J.D.E.; NESTLER, J.E.; STRAUSS, J.F. et al. Insulin regulates low density lipoprotein metabolism by swine granulose cell. Endocrinology, v.118, p.242-248, 1986.

WATHES, D.C.; REYNOLDS, T.S.; ROBINSON, R.S. et al. Role of insulin-like growth factor system in uterine function and placental development in ruminants. Journal of Dairy Science, v.81, p.1778-1789, 1998. 